\title{
Low Zinc Status Among Palestinian University Students is Related to Hair Loss But Not Diet Score
}

\author{
Alkharraz L, Natour N*, Samer M, Masri R, \\ Ayman TA, Dauod S, Thaher R, J aber A and \\ Daraghmeh A \\ Department of Bio-Medical Sciences, An-Najah National \\ University, Faculty of Medicine, Palestine \\ *Corresponding author: Nihal Natour, An-Najah \\ National University, Faculty of Medicine, Nablus, \\ Palestine
}

Received: December 31, 2020; Accepted: February 01, 2021; Published: February 08, 2021

\begin{abstract}
Introduction: Zinc is an essential nutrient that is related to many health issues, including cutaneous and hair health

Aims: To study the prevalence of low and high zinc concentrations among university students and to evaluate the association between zinc status and various health issues including hair loss, skin health, immunity, diarrhea and weight status.
\end{abstract}

Methods: Study outcomes which included age, BMI, gender, health variables such as diarrhea, hair loss, weight loss and others were collected using a structured questionnaire, whereas serum zinc concentration was measured using spectrophotometry.

Results: $33 \%$ of the study participants had low zinc level, whereas $34.7 \%$ had zinc levels higher than normal. Both high and low zinc status were associated with significant hair loss $(p<0.0001)$. High and low zinc status were not significantly related to other study outcomes such as diarrhea, acne and weight loss. Healthy diet score was not significantly different between zinc status categories and was not significantly related to other study outcomes.

Conclusion: Appropriate intake of zinc and zinc concentration may protect from hair loss and should be promoted.

\section{Introduction}

Zinc is an essential nutrient that is involved in structural proteins, many enzymes and transcription factors [1]. The prevalence of zinc deficiency globally is estimated to be $20 \%$ [2]. It is estimated that $10 \%$ of American population consume less zinc than what they need and are at risk of zinc deficiency [3]. Zinc deficiency is implicated in diarrhea [4] and supplementation of zinc was related in reducing acute and persistent diarrhea [5]. Also, zinc deficiency was linked to impaired immune system and mortality from respiratory disease especially among children [6]. Zinc deficiency is implicated in cutaneous health and hair loss [7]. Zinc is also related to neurobehavioral development [8].

Dietary sources of zinc includes meat, fish, legumes and other dietary sources and differ according to substrate. Zinc deficiency is common in developing countries such as Egypt, Turkey and Iran due to high consumption of phytate. Zinc is primarily absorbed through small intestine (distal duodenum and proximal jejunum) and it is excreted through GI tract and some secretion through urine and sweat [7]. Marginal zinc deficiency is associated with depressed immunity, impaired memory, neurosensory problems, impaired taste, smell, night blindness and decreased sperm production [9] Also, marginal zinc deficiency can decrease appetite, recent studies have found relations between zinc and leptin which is implicated in regulation of food intake and energy [9].

Zinc is abundant in skin tissues, as zinc is required for the differentiation and proliferation of keratinocytes. Deficiency of zinc is related to skin conditions such as alopecia and skin lesions [10]. The requirement of keratinization of hair to the zinc is that zinc is related to cysteine metabolism [11]. Also, zinc is required for many enzymes that are implicated in hair homeostasis and protection of hair from inflammation related alopecia [12]. In a study that addressed the association between hair loss and zinc, the serum concentration of zinc was almost $13 \mathrm{mcg} / \mathrm{dL}$ less in patients with alopecia compared to normal and that the persons with zinc concentration below $70 \mathrm{mcg} /$ $\mathrm{dL}$ was significantly higher in patients with alopecia[13]. Moreover, zinc deficiency is related to having higher prevalence of acne vulgaris which has important cosmetic and psychological concerns [14]. There is currently no data on zinc intake among Palestinians or recommendation for the public on this aspect. A study among pregnant women from Palestine showed zinc level of $4.53 \mathrm{mg} / \mathrm{L}$ (45.3 $\mathrm{mcg} / \mathrm{L}$ ) and it was associated with living in cities and having higher income [15]. Yet this study did not address various diet sources of zinc or its consequences on health. Also study of zinc intake and level among different age groups is needed. So the goals of this study is to. 1) To assess the prevalence of zinc deficiency in a group of students. 2) To understand the relationship between zinc intake and zinc serum level. 3) To evaluate many aspects related to the relationship between zinc and health outcomes including hair loss.

\section{Methods}

202 participant aged between 18-25 years old were enrolled in this study to measure zinc concentration in their blood and determine its association with several variables. Ethical approval was obtained for this study from Institution review board at An Najah National University. All participants were informed about the study, and their participation was voluntary. Information were collected from the
Austin J Nutr Metab - Volume 8 Issue 1 - 2021

Submit your Manuscript | www.austinpublishinggroup.com

Natour et al. (C) All rights are reserved Palestinian University Students is Related to Hair Loss But Not Diet Score. Austin J Nutr Metab. 2021; 8(1): 1101. 
participants regarding their diet, hair loss and many other variables listed in the questionnaire. After that, $3 \mathrm{ml}$ of blood was collected from each subject to measure the level of zinc in the plasma. The blood was spun within one hour of collection to separate the plasma from whole blood. Zinc was measured in each blood sample using colormetric method from Quimica Clinica Aplicada SA (QSA). $1 \mathrm{ml}$ of each plasma and standard solution was mixed with 50 microliter of zinc working solution and incubated at room temperature for 10 minutes before its absorbance was measured in the spectrophotometer at wavelength 560 nanometer against blank solution which was prepared by mixing $1 \mathrm{ml}$ of working solution with 50 microliter distilled water. The concentration of zinc in each sample was determined following specific equation (QSA Company). Dietary intake habits of meat, seafood, vegetable, fruits, nuts, seeds and chocolate were measured by scored questions from 0 to 3 according to frequency of intake, with highest intake given 3 and lowest intake given 0 . The scores for all diet groups were summed to give a final diet score that could reflect healthy dietary intake.

\section{Statistical analysis}

The Statistical Package for Social Science (SPSS) was used to analyze the data. Study variables were compared between categories of zinc status using chi square (Table 1) or fisher exact test according to numbers per cell. The mean of diet score was compared across categories of study variables using t-test or ANOVA. $p<0.01$ was considered significant.

\section{Results}

In this study we included 202 university students who were 18-25 $y$, only $15 \%$ were males and the rest of the group were females. $16.3 \%$ had low zinc status, $48.8 \%$ had normal zinc status and $34.5 \%$ had high serum zinc level. Majority of the study participants were from Nablus 51.2\%, whereas the rest of the students were from across cities in Palestine. Majority of the studied group had moderate hair loss (70.9\%), whereas $22.2 \%$ had a lot of hair loss. Various study variables are summarized across zinc status groups in (Table 1). Zinc status was not related to diarrhea, immunity, ulcer, acne or fatigue, but hair loss was significantly highest in adults with high or low zinc levels. Average diet score was 13.4 and $\mathrm{SD}=2.5$. There was no difference in diet score across diarrhea, immunity, ulcer, acne, fatigue, hair loss, or zinc status categories, although students with lowest zinc status had the lowest diet score, but this was not statistically significant $(\mathrm{p}=0.118)$ (Table 2).

\section{Discussion}

In a representative sample of 202 university students from Najah University, only $15 \%$ of the study were from males. $16.3 \%$ of the study participants had low zinc status, whereas $15.3 \%$ of the study were males. Only fatigue and hair loss were significantly related to zinc status. On the other hand, zinc status categories and zinc related diet score was not related to diarrhea, acne, weight loss, ulcer, weak immunity, vision. Diet score related to zinc intake was not significantly related to zinc status categories or hair loss, although people who had more hair loss and were hypo in zinc tended to eat less food high in zinc, but this was not significant.

The range of zinc deficiency is lower than what was reported globally (20\%) [2]. In a study among patients with diabetes mellitus
Table 1: The distribution of study variables according category of zinc status.

\begin{tabular}{|c|c|c|c|c|c|}
\hline Variable & Hypo & Hyper & Normal & $p$-value & $\mathrm{p}$-value \\
\hline \multicolumn{6}{|l|}{ Diarrhea } \\
\hline Yes & $1(3 \%)$ & $4(6 \%)$ & $3(3 \%)$ & 0.65 & 0.46 \\
\hline No & 32 (97\%) & $66(94 \%)$ & $96(97 \%)$ & & \\
\hline \multicolumn{6}{|l|}{ Ulcer } \\
\hline Yes & $7(21.2 \%)$ & $13(18.6 \%)$ & $25(25.3 \%)$ & 0.58 & \\
\hline No & $26(79 \%)$ & 57 (81.4\%) & 74 (74.7\%) & & \\
\hline \multicolumn{6}{|c|}{ Weight loss } \\
\hline Yes & $4(12.1 \%)$ & 9 (12.9\%) & $15(15.2 \%)$ & & \\
\hline No & $29(88 \%)$ & $61(87 \%)$ & $84(85 \%)$ & & \\
\hline \multicolumn{6}{|l|}{ Ulcers } \\
\hline Yes & 7 (21.2\%) & $13(18.6 \%)$ & 25 (25.3\%) & 0.58 & \\
\hline No & $26(78.8 \%)$ & 57 (81.4\%) & 74 (74.7\%) & & \\
\hline \multicolumn{6}{|l|}{ Fatigue } \\
\hline Yes & $20(60.6 \%)$ & 38 (54.3\%) & $72(72.7 \%)$ & 0.04 & \\
\hline No & $13(39.4 \%)$ & 32 (45.7\%) & $27(27.3 \%)$ & & \\
\hline \multicolumn{6}{|l|}{ Acne } \\
\hline Yes & 15 (45.5\%) & $34(48.6 \%)$ & 53 (53.5\%) & 0.67 & \\
\hline No & 18 (54.5\%) & 36 (51.4\%) & $46(46.5 \%)$ & & \\
\hline \multicolumn{6}{|c|}{ Weak immunity } \\
\hline Yes & $10(30 \%)$ & $14(20 \%)$ & $29(29 \%)$ & 0.34 & \\
\hline No & $23(70 \%)$ & $56(80 \%)$ & $70(71 \%)$ & & \\
\hline \multicolumn{6}{|l|}{ Vision } \\
\hline Yes & $12(36.5 \%)$ & $23(33 \%)$ & $29(29 \%)$ & 0.73 & \\
\hline No & $21(64 \%)$ & 47 (67\%) & $70(71 \%)$ & & \\
\hline \multicolumn{6}{|l|}{ Hair loss } \\
\hline little & $1(3 \%)$ & $2(3 \%)$ & $8(8 \%)$ & 0 & 0 \\
\hline moderate & $21(64 \%)$ & $39(56 \%)$ & $84(85 \%)$ & & \\
\hline a lot & $11(33 \%)$ & 29 (41.4\%) & $5(5.1 \%)$ & & \\
\hline do not & 0 & 0 & $2(2 \%)$ & & \\
\hline
\end{tabular}

type $2,19 \%$ of them were zinc deficient [16]. In a study by Hotz et al., the average of zinc intake of people in North Africa and Middle East is $15.4 \mathrm{mg} \pm 2.2 \mathrm{mg} / \mathrm{day}$, whereas $9.3 \%$ of them are estimated to be at risk of deficiency [17]. We did not find many studies of the deficiency on zinc in young adults in countries in Middle East as many studies have focused on children [18]. However zinc is available in similar dietary sources as iron, of which deficiency is highly prevalent globally [17] and in Palestine [19].

It is worthy to mention that zinc deficiency in this study was not related significantly to lower intake of healthy foods score. Zinc is present in animal source such as beef, poultry, fish, shellfish and lesser amount in eggs and dairy products. Also, nuts, seeds, legumes, whole grain cereals, but low in fruits, vegetables. Dietary factors can modify zinc absorption by 10 folds. Mainly Phytates and calcium can reduce zinc absorption, whereas proteins can enhance zinc absorption [20]. Also, the higher the zinc content of food, the less is the amount absorbed. Phytates is phosphorous storage molecule that is present in high amounts in seeds, cereal grains, nuts, legumes but lower 
Table 2: Comparison between diet score between various categories of study variables.

\begin{tabular}{|c|c|c|c|c|}
\hline \multicolumn{5}{|l|}{ 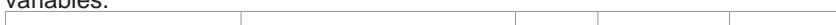 } \\
\hline Variable & Mean of diet score & SD & t-value & $\mathrm{p}$-value \\
\hline \multicolumn{5}{|l|}{ Diarrhea } \\
\hline Yes $(n=8)$ & 13.5 & 4.3 & 0.06 & 0.96 \\
\hline No $(n=194)$ & 13.45 & 2.2 & & \\
\hline \multicolumn{5}{|l|}{ Weight loss } \\
\hline Yes $(n=28)$ & 14.1 & 2.9 & 1.6 & 0.11 \\
\hline No $(n=174)$ & 13.4 & 2.2 & & \\
\hline \multicolumn{5}{|l|}{ Ulcer } \\
\hline Yes ( 45) & 14 & 2.6 & 1.7 & 0.09 \\
\hline No (175 ) & 13.3 & 2.2 & & \\
\hline
\end{tabular}

\section{Fatigue}

\begin{tabular}{|l|l|l|l|l|}
\hline Yes (130) & 13.4 & 2.3 & -0.6 & 0.52 \\
\hline No (72) & 13.6 & 2.5 & & \\
\hline
\end{tabular}

Acne

\begin{tabular}{|l|l|l|l|l|}
\hline Yes (102) & 13.6 & 2.3 & 0.81 & 0.41 \\
\hline No (100) & 13.3 & 2.4 & & \\
\hline
\end{tabular}

\begin{tabular}{|l|l|l|l|l|}
\hline Weak immunity \\
\hline Yes (53) & 13.5 & 2.9 & 0.13 & 0.9 \\
\hline No (149) & 13.4 & 2.1 & & \\
\hline
\end{tabular}

\begin{tabular}{|c|c|c|c|c|}
\hline No (149) & 13.4 & 2.1 & & \\
\hline \multicolumn{5}{|l|}{ Vision } \\
\hline Yes (64) & 13.3 & 2.7 & -0.53 & 0.6 \\
\hline No (138) & 13.5 & 2.1 & & \\
\hline
\end{tabular}

\section{Zinc Status}

\begin{tabular}{|l|l|l|l|l|}
\hline Hypo (33) & 12.9 & 2.4 & $\mathrm{~F}=2.2$ & 0.118 \\
\hline Hyper (70) & 13.9 & 2.4 & & \\
\hline Normal (99) & 13.3 & 2.3 & & \\
\hline
\end{tabular}

\begin{tabular}{|l|c|c|c|c|}
\hline Hair loss & 13.9 & 1.9 & $\mathrm{~F}=0.46$ & $\mathrm{P}=0.71$ \\
\hline Little(11) & 13.4 & 2.4 & & \\
\hline Moderate (144) & 15 & 1.4 & & \\
\hline Don't (2) & 13.5 & 2.4 & & \\
\hline A lot (45) & \multicolumn{4}{|l|}{} \\
\hline Hijab (females) & 13.4 & 2.3 & $\mathrm{t}=1.76$ & $\mathrm{p}=0.08$ \\
\hline Yes (163) & 12 & 2.1 & & \\
\hline No (8) & 13.8 & 2.4 & $\mathrm{t}=0.91$ & $\mathrm{p}=0.36$ \\
\hline Gender & 13.4 & 2.3 & & \\
\hline Male (31) & & & \\
\hline Female (171) & & & \\
\hline
\end{tabular}

in fruits and vegetables. In the data that we used to assess diet, we evaluated the diet based on high intake of healthy food regardless of zinc content and we did not consider Phytates and calcium content of food. The Phytates tends to chelate and decrease zinc absorption in dose dependent manner [17].

A significant association was found between zinc categories and hair loss in unadjusted models. Lower level of zinc was more prevalent in groups with more hair loss. $22.2 \%$ of the total sample has high hair loss and $71 \%$ of total sample has moderate hair loss. When we repeated the analysis for females only, similar results were found. We did not study the relationship between hair loss and zinc in the context of other nutrients. Other nutrients are implicated in hair loss such as vitamin $A$, vitamin $B$, vitamin $C$, vitamin $D$, vitamin $E$, iron, selenium, in addition to zin [21]. In this study, high diet score is not significantly related to hair loss in our study, may be other studies that capture nutrients related to hair loss are needed.

No association between zinc and many other study outcomes, including diarrhea, ulcer, acne, immunity, may be the results were in fact related to the fact the study was cross sectional in its design and longitudinal other study designs are needed to capture the relationship, or the fact that prevalence of zinc deficiency in our study was not high enough to capture the differences, hence other studies are needed to clarify the relationship.

We did not find association between the Islamic dress code and zinc concentration. Studies on the association between nutrition related factors such as vitamin D and hijab, found that this social category could be at higher risk [22], however this was not manifested in our study, as it was shown that diet score was not significantly related to dress code. Indeed in our study, the diet score was slightly higher among women with head cover, but this did not reach statistical significance $(\mathrm{p}=0.08)$. This study not without limitation, including its cross sectional design. Also, males were under-represented. Also, we used general method to capture diet and not diet specific dietary assessment tool. Also, we did not adjust our diet evaluation to total calories intake. However, this study was the first to address the association between zinc status to diet and various health outcomes.

In summary, in this study we present modest prevalence of zinc deficiency. Diet score was not related zinc status categories. Zinc status category was significantly related to hair loss, however it was not significantly related to other health outcomes including diarrhea, acne, ulcer, immunity. In addition, diet score was not significantly related to health outcomes and hair loss. More studies in relation to zinc status should be performed in Palestinian society.

\section{References}

1. Tuerk MJ, Fazel N. Zinc deficiency. Current Opinion in Gastroenterology. 2009; 25: 136-143.

2. Wuehler SE, Peerson JM, Brown $\mathrm{KH}$. Use of national food balance data to estimate the adequacy of zinc in national food supplies: methodology and regional estimates. Public Health Nutr. 2005; 8: 812-819.

3. Wakimoto P, Block G. Dietary intake, dietary patterns, and changes with age: an epidemiological perspective. The Journals of Gerontology Series A: Biological Sciences and Medical Sciences. 2001; 56: 65-80.

4. Ruz M, Solomons NW. Mineral excretion during acute, dehydrating diarrhea treated with oral rehydration therapy. Pediatric Research. 1990; 27: 170-175.

5. MacDonald RS. The role of zinc in growth and cell proliferation. The Journa of nutrition. 2000; 130: 1500S-1508S.

6. Hambidge KM, Krebs NF. Zinc deficiency: a special challenge. The Journal of nutrition. 2007; 137: 1101-1105.

7. Maxfield L, Crane JS. Zinc deficiency, in StatPearls. 2019.

8. Wessells KR, Brown KH. Estimating the global prevalence of zinc deficiency: results based on zinc availability in national food supplies and the prevalence of stunting. PloS one. 2012; 7: e50568.

9. Sauer AK, Hagmeyer S, Grabrucker AM. Zinc deficiency. Nutritional deficiency. Intact open science. 2016: 23-46. 
10. Ogawa Y, Kawamura T, Shimada S. Zinc and skin biology. Archives of biochemistry and biophysics. 2016; 611: 113-119.

11. Follis RH, Day HG, McCollum E. Histological Studies of the Tissues of Rats Fed a Diet Extremely Low in Zinc: Two Plates (Eleven Figures). The Journa of Nutrition. 1941; 22: 223-237.

12. Rink L, Haase H. Zinc homeostasis and immunity. Trends in immunology 2007; 28: 1-4.

13. Kil MS, Kim CW, Kim SS. Analysis of serum zinc and copper concentrations in hair loss. Annals of Dermatology. 2013; 25: 405-409.

14. Goodarzi A, Roohaninasab M, Atefi NS, Bazargan AS, Ghassemi M Ghahremani AP, et al. Determination of serum levels of zinc in acne vulgaris patients: a case control study. Iranian Journal of Dermatology. 2020; 23: 2831.

15. Shawahna R, Zyoud A, Jallad D, Hadwan L, Ihssan N, Hilal H, et al. Blood zinc levels in nursing women from different regions of the West Bank of Palestine. Women \& health. 2018; 58: 822-833.
16. Daradkeh G. Zinc status among type (2) diabetes mellitus in the State of Qatar. Public Health Front. 2014; 3: 4-10.

17. Hotz $\mathrm{C}$, Brown $\mathrm{KH}$. Assessment of the risk of zinc deficiency in populations and options for its control. 2004.

18. Jallad D, Ihsan N, abu Hadwan L. Blood Zinc Levels in Nursing Women from Different Regions of the West Bank of Palestine. 2016.

19. Natour N, Mariam A, abo Al Rob A. Factors associated with patterns of weight gain among pregnant women in northern west bank area of Nablus. 2020.

20. Loonnerdal B. Dietary Factors Influencing Zinc Absorption. The Journal of Nutrition. 2000; 130: 1378S-1383S.

21. Almohanna HM, Ahmed AA, Tsatalis JP, Tosti A. The role of vitamins and minerals in hair loss: a review. Dermatology and therapy. 2019; 9: 51-70.

22. Hameed WE, Witwit GT, Ghazala AD. Vitamin D Status with Obesity in Patients Attending Nutrition Clinic at Al-Sadiq Hospital. Indian Journal of Public Health Research \& Development. 2019; 10: 1228-1233. 